\title{
Thermally Regulated Reversible Formation of Vesicle-Like Assemblies by Hexaproline Amphiphiles
}

\author{
Carles Felip-León, Francisco Galindo, ${ }^{(0)}$ and Juan F. Miravet*(i) \\ Departament de Química Inorgànica i Orgànica, Universitat Jaume I, Avda Sos Baynat s/n, 12071 Castelló, Spain
}

\author{
Valeria Castelletto ${ }^{\circledR}$ and Ian W. Hamley*(1) \\ Department of Chemistry, University of Reading, Whiteknights, Reading RG6 6AD, U.K.
}

\section{Supporting Information}

ABSTRACT: Peptides composed of hexaproline and glutamic acid $\left(\mathrm{P}_{6} \mathrm{E}\right)$ or lysine $\left(\mathrm{P}_{6} \mathrm{~K}\right)$ as $\mathrm{C}$-terminal units show thermally promoted aggregation, affording vesicle-like assemblies upon heating to $80^{\circ} \mathrm{C}$. The aggregation is analyzed by dynamic light scattering (DLS), with number-averaged diameters of ca. 600 and $300 \mathrm{~nm}$, respectively, for $\mathrm{P}_{6} \mathrm{E}$ and $\mathrm{P}_{6} \mathrm{~K}$. NMR studies reveal that upon heating the amount of NMR-visible species is reduced to ca. $50 \%$ and that an important conformational change is experienced by the molecules in solution. Circular dichroism (CD) shows that at $20{ }^{\circ} \mathrm{C}$ the peptides present a polyproline II (PP-II) conformation which is disorganized upon heating. Scanning electron microscopy for samples which were fast frozen at $80^{\circ} \mathrm{C}$ reveals vesicle-like assemblies. Using pyrene as a fluorescence probe, a critical aggregation concentration of ca. $30 \mu \mathrm{M}$ was estimated for $\mathrm{P}_{6} \mathrm{E}$, while that of $\mathrm{P}_{6} \mathrm{~K}$ was above $0.6 \mathrm{mM}$. The aggregation process is found to be fully reversible and could serve as a basis for development of stimuli responsive carriers.

\section{INTRODUCTION}

Peptide self-assembly has received increasing interest in the last years due to its relevance in difference biological processes. In particular, aggregation of peptides to give fibers is common as a result of 1-D growth of fibrils promoted by intermolecular $\mathrm{H}$ bonding interactions. Fundamental studies of this process have implications in the diseases such as amyloid-type fibrillization and in the formation of peptide-derived supramolecular gels. ${ }^{1,2}$ Vesicle formation by peptides is much less common than fibrillization. Several cases have been reported using, for example, glycine-rich surfactant-like peptides, ${ }^{3,4}$ sequenced peptides, ${ }^{5}$ and diphenylglycine in aqueous solution ${ }^{6}$ or Bocdiphenylalanine [Boc: tert-butoxycarbonyl] in organic solvents. $^{7,8}$

Here we report on unprecedented formation of vesicle-like structures by oligoproline amphiphiles (Scheme 1). Polyproline (PP) domains are present in proteins prone to fibrillation such as collagen and play an important role in protein-protein and protein-nucleic acid interactions. ${ }^{9}$ PP peptides are considered to be rather rigid domains in protein structures and have received attention due to their use as molecular rulers for fluorescence resonance energy transfer (FRET) calibration studies. $^{10,11} \mathrm{PP}$ in water presents predominantly the so-called PP-II arrangement, a left-handed helix with an all-trans amide configuration and a repeat distance of $3.1 \AA .^{12}$ The PP-I structure, with an all-cis amide configuration, is a right-handed

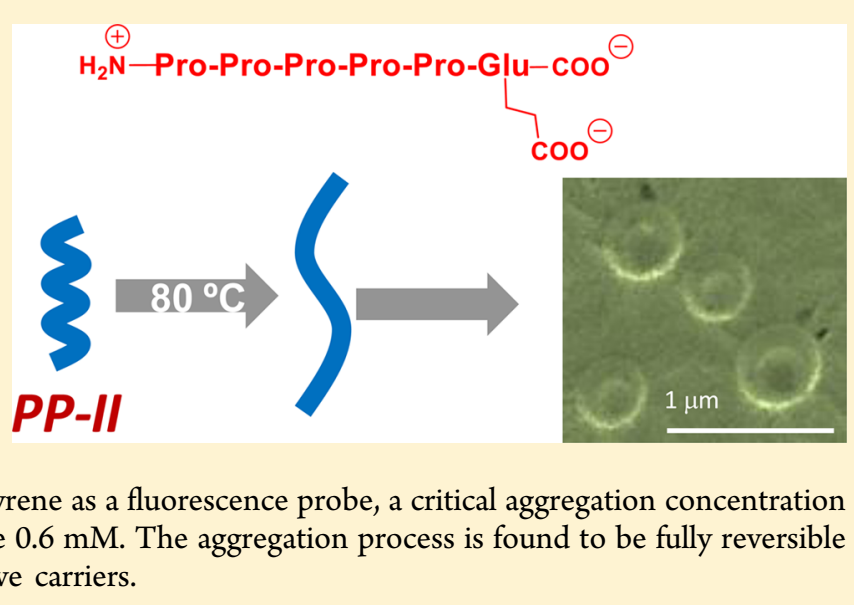

Scheme 1. Schematic of the Process of Formation of VesicleLike Assemblies for Peptide $\mathrm{P}_{6} \mathrm{E}$

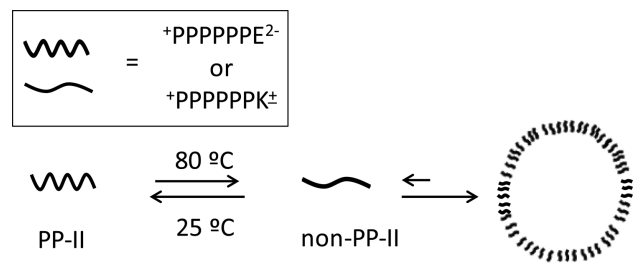

helix observed in organic solvents. ${ }^{13}$ The aggregation of PP motifs in water has been scarcely studied. Tertiary amides lack amide protons for intermolecular H-bonding, and one would expect that PP cannot aggregate in a similar way to other peptides. However, it has been described recently that PP precipitates in aqueous solution to give a thin film above a certain concentration threshold (ca. $1 \mathrm{mg} / \mathrm{mL}$ ) at high temperatures. $^{14}$ In earlier reports, the precipitation upon heating above ca. $55{ }^{\circ} \mathrm{C}$ of PP in water was studied by $I R^{15,16}$ The interaction of the carbonyl groups of the PP with the solvent seems to be a key issue in the observed behavior. Upon heating, the weakening of these interactions leads to

Received: June 23, 2017

Revised: July 14, 2017

Published: July 18, 2017 
precipitation which is probably associated also with a slight conformational change. Circular dichroism spectroscopy and vibrational circular dichroism (VCD) spectroscopy along with Raman and FTIR methods have been used to investigate the conformation of a model triproline peptide in water. ${ }^{17}$ VCD has been used to investigate in detail the conformation of oligoproline peptides $\left(\mathrm{P}_{2}-\mathrm{P}_{12}\right)$ in aqueous solutions. ${ }^{18,19} \mathrm{~A}$ reversible conformational transition from PP-I to PP-II upon heating has been observed for a $\mathrm{P}_{12}$ peptide in $n$-propanol by $\mathrm{CD}$, and it was associated with the cis-trans isomerization of amide bonds. ${ }^{20}$ The transition kinetics and thermodynamics were also analyzed. Peptide $\mathrm{P}_{6}$ also shows a concentrationdependent transition between PP-I and PP-II in aqueous $n$ propanol. $^{21}$ However, no aggregation process has been reported for unmodified oligoproline peptides, to our knowledge.

\section{RESULTS AND DISCUSSION}

Hexaproline peptides containing as a C-terminal unit the ionizable amino acids glutamic acid $\left(\mathrm{P}_{6} \mathrm{E}\right)$ or lysine $\left(\mathrm{P}_{6} \mathrm{~K}\right)$ were studied in phosphate-buffered water at $\mathrm{pH} 7$ (Scheme 1). Assuming that the $\mathrm{p} K_{\mathrm{a}}$ values do not differ to a great degree from those reported for proline and glutamic acid in peptides, at neutral $\mathrm{pH}, \mathrm{P}_{6} \mathrm{E}$ should exist as a singly charged anion with partial positive charge in the $\mathrm{N}$-terminal proline unit and the $\mathrm{C}$ terminal glutamic acid unit as a dianion. On the other side, $\mathrm{P}_{6} \mathrm{~K}$ should predominantly form a cationic species at $\mathrm{pH} 7$ as a result of the protonation of $\mathrm{N}$-terminal proline and $\mathrm{C}$-terminal lysine units together with the anionic character of the $\mathrm{C}$ terminal carboxylate (Figure 1).
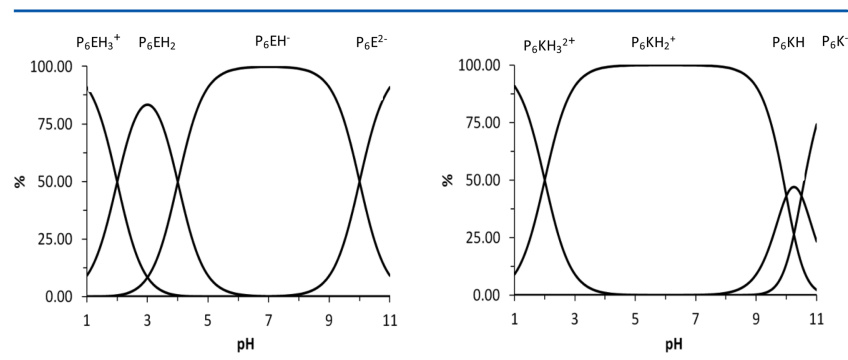

Figure 1. Species distribution diagrams calculated for $\mathrm{P}_{6} \mathrm{E}$ and $\mathrm{P}_{6} \mathrm{~K}$ in aqueous media (estimated $\mathrm{p} K_{\mathrm{a}}$ values $=2.0,4.0,10.0$, and 10.5 for $\mathrm{C}$ terminus, $\mathrm{E}$ residue, $\mathrm{N}$ terminus, and $\mathrm{K}$ residue, respectively).

Dynamic light scattering (DLS) studies carried out at $25^{\circ} \mathrm{C}$ indicate the presence of free, nonaggregated species both for $\mathrm{P}_{6} \mathrm{E}$ and $\mathrm{P}_{6} \mathrm{~K}$ with an average size of ca. $1 \mathrm{~nm}$ (Figure 2). Remarkably, upon heating up to $80{ }^{\circ} \mathrm{C}$, aggregation into objects with low polydispersity objects ascribable to vesicle-like assemblies is observed. In the case of $\mathrm{P}_{6} \mathrm{E}$, a number-averaged
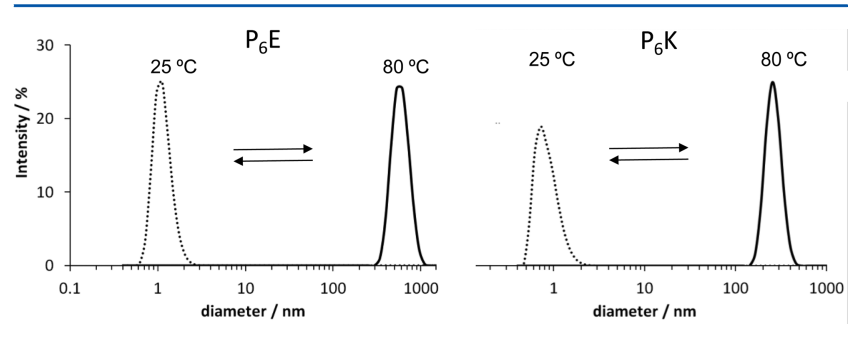

Figure 2. DLS analysis (number-averaged diameters) of $\mathrm{P}_{6} \mathrm{E}$ and $\mathrm{P}_{6} \mathrm{~K}$ $(1 \% \mathrm{w} / \mathrm{w}, \mathrm{pH} 7)$ at 25 and $80{ }^{\circ} \mathrm{C}$. diameter $\left(D_{\mathrm{n}}\right)$ of ca. $600 \mathrm{~nm}$ is detected, while the assemblies formed by $\mathrm{P}_{6} \mathrm{~K}$ were smaller with a diameter of ca. $300 \mathrm{~nm}$ (Figure 2). The aggregation process is found to be fully reversible, and upon cooling down back to $25^{\circ} \mathrm{C}$, free $\mathrm{P}_{6} \mathrm{E}$ and $\mathrm{P}_{6} \mathrm{~K}$ is observed again by DLS.

Circular dichroism experiments were carried out at $0.1 \% \mathrm{w} / \mathrm{w}$ to avoid signal saturation. At $25{ }^{\circ} \mathrm{C}$, the characteristic pattern of a PP-II conformation ${ }^{18,22,23}$ with positive ellipticity at $228 \mathrm{~nm}$ was observed for both peptides (Figure 3). Upon heating up to $80{ }^{\circ} \mathrm{C}$, the PP-II pattern disappears, indicating an important conformational change taking place. The change was found to occur gradually with the increasing temperature with no critical point observed (Figure S2). In accordance with DLS measurements, the process is fully reversible, and upon cooling back to $20^{\circ} \mathrm{C}$, the PP-II conformation is recovered. Difference spectra were plotted, showing an increasing deviation from PPII conformation on heating with a development of a spectrum with a maximum near $200 \mathrm{~nm}$ and a minimum near $220 \mathrm{~nm}$, suggesting the appearance of turn or $\beta$-sheet structures ${ }^{24-27}$ (Figure S3).
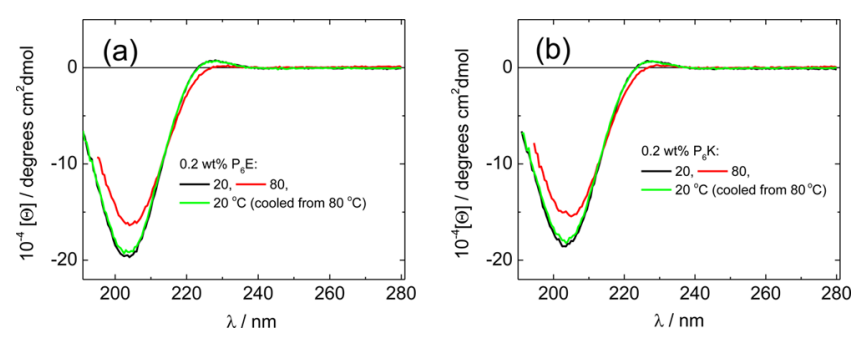

Figure 3. $\mathrm{CD}$ spectra of $\mathrm{P}_{6} \mathrm{E}$ and $\mathrm{P}_{6} \mathrm{~K}(0.1 \% \mathrm{w} / \mathrm{w}, \mathrm{pH} 7)$ at 20 and 80 ${ }^{\circ} \mathrm{C}$.

These results are fully consistent with NMR measurements. Upon heating to $80{ }^{\circ} \mathrm{C}$, the ${ }^{1} \mathrm{H}$ NMR-visible species were reduced to ca. $50 \%$ using an internal standard for integration. This fact proves the formation of large, NMR-silent aggregates. Interestingly, ${ }^{1} \mathrm{H}$ NMR spectra revealed that the multiplicity pattern of the signals corresponding to the diasterotopic protons at position 3 in the proline ring is heavily modified, indicating important conformational changes (Figure 4). Additionally, the traces of ${ }^{1} \mathrm{H}-{ }^{15} \mathrm{~N}$ long-range correlations, carried out for the ${ }^{15} \mathrm{~N}$-enriched sample at proline unit number 5 , also reveal important changes in the complex multiplicity pattern of the signals corresponding to the proline ring (Figure S4).

Imaging the vesicle-like assemblies by cryo-TEM and AFM was found to be challenging because of their instability at room temperature. Nevertheless, scanning electron microscopy (SEM) images were obtained from samples at $80{ }^{\circ} \mathrm{C}$ that were fast frozen and lyophilized. As can be seen in Figure 5, round shaped objects are observed which are ascribable to vesicle-like assemblies with variable diameters. These objects do not correspond to artifacts arising from salts in the buffer solution, which emerged as brilliant not-round spots that can be easily distinguished from the vesicles (Figure S9). The diameter of the vesicle-like assemblies is only in rough agreement with DLS, since the SEM images show considerable polydispersity in size. It has to be taken into account that the manipulation process of the sample (fast freezing and lyophilization) could affect the structures present in solution, leading to aggregation and increased polydispersity. Some of the observed vesicle-like assemblies revealed their hollow structure as a result of the 


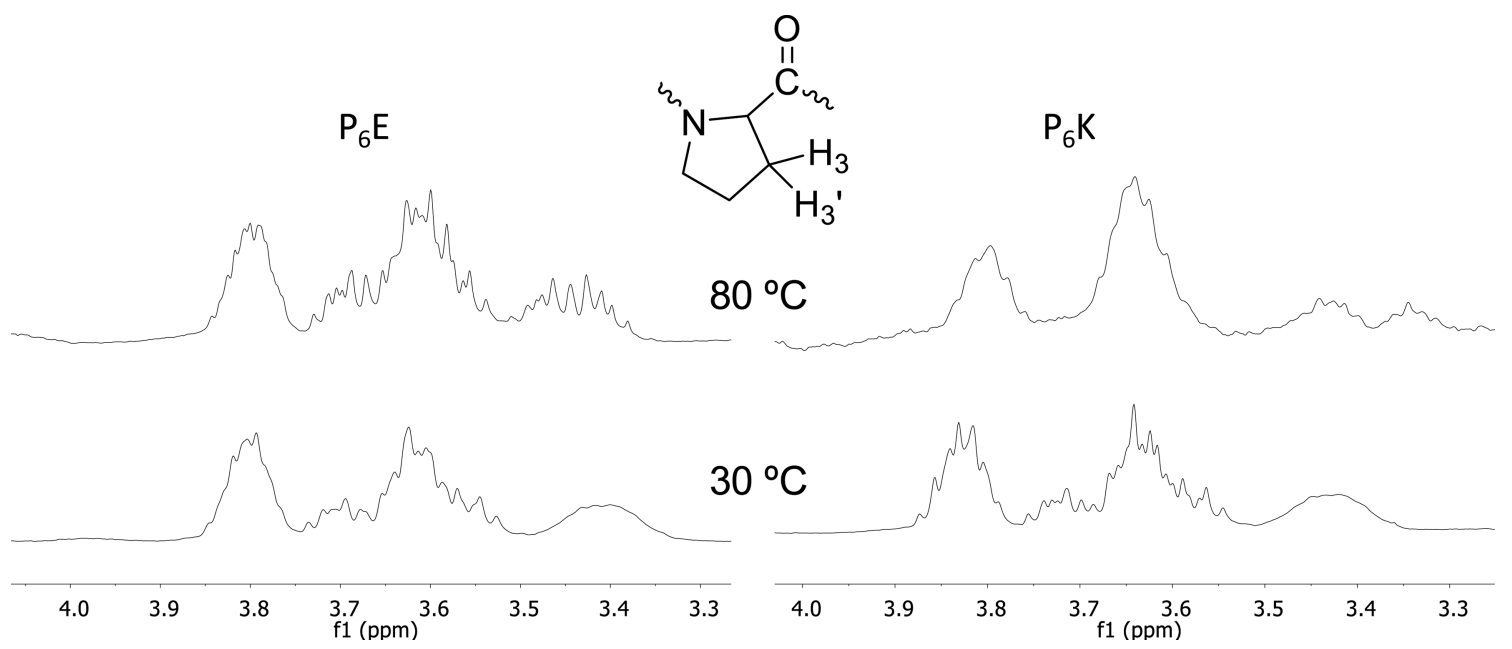

Figure 4. Partial ${ }^{1} \mathrm{H}$ NMR spectra of $\mathrm{P}_{6} \mathrm{E}$ and $\mathrm{P}_{6} \mathrm{~K}(0.1 \% \mathrm{w} / \mathrm{w}, \mathrm{pH} 7)$ at 25 and $80{ }^{\circ} \mathrm{C}$.
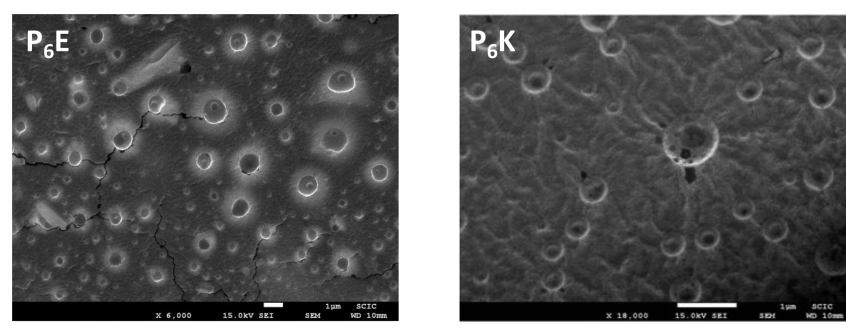

Figure 5. Scanning electron microscopy images of vesicle-like assemblies of $\mathrm{P}_{6} \mathrm{E}$ and $\mathrm{P}_{6} \mathrm{~K}(1 \% \mathrm{w} / \mathrm{w})$ formed at $80{ }^{\circ} \mathrm{C}$ in phosphate buffer at $\mathrm{pH}$ 7. The sample was fast frozen and lyophilized prior to observation. Scale bars are $1 \mu \mathrm{m}$ long.

observation under the electron beam, resulting in donut-like objects.

The self-assembly process was followed using pyrene as a fluorescent probe (Figure 6). Upon heating, and subsequent

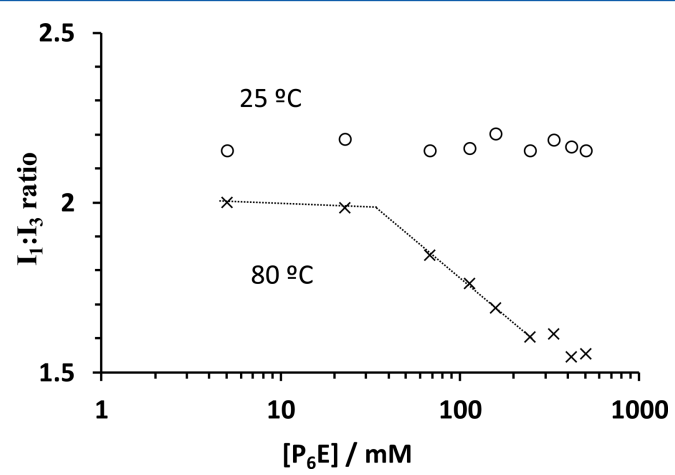

Figure 6. Variation of the relative intensity of fluorescence signals $I_{1}$ and $I_{3}$ of pyrene $(1 \mu \mathrm{M})$ in the presence of $\mathrm{P}_{6} \mathrm{E}$ in phosphate buffer, $\mathrm{pH}$ 7. $\lambda_{\text {exc }}=350 \mathrm{~nm}, \lambda_{1}=370.5 \mathrm{~nm}, \lambda_{3}=381 \mathrm{~nm}$.

$\mathrm{P}_{6} \mathrm{E}$ aggregation, incorporation of pyrene into a hydrophobic environment ${ }^{28,29}$ was clearly detected by measuring the relative intensity of its vibronic fluorescence bands 1 and 3 . The trend in $I_{1} / I_{3}$ as a function of concentration is similar to that noted for conventional amphiphiles for which $I_{1} / I_{3}$ decreases at the critical micelle concentration, from a typical value of around $1.7-1.8$ to a lower value. ${ }^{30,31}$ The critical concentration for aggregation at $80{ }^{\circ} \mathrm{C}$ of $\mathrm{P}_{6} \mathrm{E}$ was found to be as low as ca. 30 $\mu \mathrm{M}$, revealing a strongly thermodynamically favorable aggrega- tion process. In constrast to $\mathrm{P}_{6} \mathrm{E}$, no critical point was observed in the fluorescence of pyrene in the presence of $\mathrm{P}_{6} \mathrm{~K}$ at $80^{\circ} \mathrm{C}$ in the range of concentrations used (upper limit was $0.6 \mathrm{mM}$ ). This result indicates that the aggregation of $\mathrm{P}_{6} \mathrm{~K}$ is thermodynamically less favorable than that of $\mathrm{P}_{6} \mathrm{E}$.

\section{CONCLUSIONS}

Peptide amphiphiles $\mathrm{P}_{6} \mathrm{E}$ and $\mathrm{P}_{6} \mathrm{~K}$ at $\mathrm{pH} 7$ and $25^{\circ} \mathrm{C}$ present a $\mathrm{PP}-\mathrm{II}$ conformation as revealed by $\mathrm{CD}$, showing no aggregation. Upon heating, an important conformational change takes place, with the peptides losing their secondary structure according to CD. NMR studies confirm an important conformational reorganization which strongly affects the multiplicity pattern of the proline ring protons. The conformation adopted at $80^{\circ} \mathrm{C}$ is accompanied by aggregation into vesicle-like assemblies which are detected as rather monodisperse objects by DLS with diameters of ca. 600 and $300 \mathrm{~nm}$ for $\mathrm{P}_{6} \mathrm{E}$ and $\mathrm{P}_{6} \mathrm{~K}$, respectively. The aggregation is found to be fully reversible, with the system recovering the PP-II conformation upon cooling back to $25^{\circ} \mathrm{C}$. Scanning electron microscopy images from samples at $80{ }^{\circ} \mathrm{C}$ which were fast frozen confirm the formation of vesicle-like assemblies. The aggregation onset at $80{ }^{\circ} \mathrm{C}$ was studied monitoring the fluorescence of pyrene. It was found that $\mathrm{P}_{6} \mathrm{E}$ shows a quite low critical aggregation concentration of ca. 30 $\mu \mathrm{M}$ in contrast to that for $\mathrm{P}_{6} \mathrm{~K}$, which is above $0.6 \mathrm{mM}$. In summary, we have observed the remarkable thermoreversible formation of vesicle-like assemblies by the surfactant-like peptides $\mathrm{P}_{6} \mathrm{E}$ and $\mathrm{P}_{6} \mathrm{~K}$. This transition is accompanied by, or driven by, a change in peptide conformation from PPII. To our knowledge, this is the first observation of such a phenomenon for peptide materials. The discovery of polyproline-rich peptide vesicles has great potential in the development of responsive delivery systems (e.g., drug delivery) among other future applications. In this regard, design of related polyproline amphiphiles with a lower transition temperature or responsive to other physicochemical stimuli could be evaluated in future work.

\section{ASSOCIATED CONTENT}

S Supporting Information

The Supporting Information is available free of charge on the ACS Publications website at DOI: 10.1021/acs.jpcb.7b06167. 
Details on DLS, CD, and fluorescence studies as well as on electron microscopy (PDF)

\section{AUTHOR INFORMATION}

\section{Corresponding Authors}

*E-mail: miravet@uji.es.

*E-mail: i.w.hamley@reading.ac.uk.

ORCID ${ }^{\circ}$

Francisco Galindo: 0000-0003-0826-6084

Juan F. Miravet: 0000-0003-0946-3784

Valeria Castelletto: 0000-0002-3705-0162

Ian W. Hamley: 0000-0002-4549-0926

Notes

The authors declare no competing financial interest.

\section{ACKNOWLEDGMENTS}

Ministerio de Economía y Competitividad of Spain (grant CTQ2015-71004-R) and Universitat Jaume I (grant P1.1B2015-76) are thanked for financial support. EPSRC (UK) is acknowledged for the award of a Platform grant (ref EP/LP20599/1). C.F.-L. thanks Government of Spain for a predoctoral fellowship (BES-2013-063296).

\section{REFERENCES}

(1) Hamley, I. W. The Amyloid Beta Peptide: A Chemist's Perspective. Role in Alzheimer's and Fibrillization. Chem. Rev. 2012, 112, 5147-5192.

(2) Tomasini, C.; Castellucci, N. Peptides and Peptidomimetics that Behave as Low Molecular Weight Gelators. Chem. Soc. Rev. 2013, 42, 156-172.

(3) Santoso, S.; Hwang, W.; Hartman, H.; Zhang, S. Self-Assembly of Surfactant-Like Peptides with Variable Glycine Tails to Form Nanotubes and Nanovesicles. Nano Lett. 2002, 2, 687-691.

(4) Vauthey, S.; Santoso, S.; Gong, H.; Watson, N.; Zhang, S. Molecular Self-Assembly of Surfactant-Like Peptides to Form Nanotubes and Nanovesicles. Proc. Natl. Acad. Sci. U. S. A. 2002, 99, 5355-5360.

(5) van Hell, A. J.; Costa, C. I. C. A.; Flesch, F. M.; Sutter, M.; Jiskoot, W.; Crommelin, D. J. A.; Hennink, W. E.; Mastrobattista, E. Self-Assembly of Recombinant Amphiphilic Oligopeptides into Vesicles. Biomacromolecules 2007, 8, 2753-2761.

(6) Reches, M.; Gazit, E. Formation of Closed-Cage Nanostructures by Self-Assembly of Aromatic Dipeptides. Nano Lett. 2004, 4, 581585 .

(7) Adler-Abramovich, L.; Gazit, E. Controlled Patterning of Peptide Nanotubes and Nanospheres Using Inkjet Printing Technology. J. Pept. Sci. 2008, 14, 217-223.

(8) Adler-Abramovich, L.; Kol, N.; Yanai, I.; Barlam, D.; Shneck, R. Z.; Gazit, E.; Rousso, I. Self-Assembled Organic Nanostructures with Metallic-Like Stiffness. Angew. Chem., Int. Ed. 2010, 49, 9939-9942.

(9) Adzhubei, A. A.; Sternberg, M. J. E.; Makarov, A. A. PolyprolineII Helix in Proteins: Structure and Function. J. Mol. Biol. 2013, 425, 2100-2132.

(10) Stryer, L.; Haugland, R. P. Energy Transfer: A Spectroscopic Ruler. Proc. Natl. Acad. Sci. U. S. A. 1967, 58, 719-726.

(11) Dolghih, E.; Ortiz, W.; Kim, S.; Krueger, B. P.; Krause, J. L.; Roitberg, A. E. Theoretical Studies of Short Polyproline Systems: Recalibration of a Molecular Ruler. J. Phys. Chem. A 2009, 113, 46394646.

(12) Bochicchio, B.; Tamburro, A. M. Polyproline II Structure in Proteins: Identification by Chiroptical Spectroscopies, Stability, and Functions. Chirality 2002, 14, 782-792.

(13) Kakinoki, S.; Hirano, Y.; Oka, M. On the Stability of Polyproline-I and II Structures of Proline Oligopeptides. Polym. Bull. 2005, 53, 109-115.
(14) Tooke, L.; Duitch, L.; Measey, T. J.; Schweitzer-Stenner, R. Kinetics of the Self-Aggregation and Film Formation of Poly-L-Proline at High Temperatures Explored by Circular Dichroism Spectroscopy. Biopolymers 2010, 93, 451-457.

(15) Grishkovskiï, B. A.; Khromova, T. B.; Lazarev, I. A. Aggregation of Poly-L-Proline in Aqueous Solution. Molekulyarnaya Biologiya 1981, $15,310-315$

(16) Swenson, C. A.; Formanek, R. Infrared Study of Poly-L-Proline in Aqueous Solution. J. Phys. Chem. 1967, 71, 4073-4077.

(17) Schweitzer-Stenner, R.; Eker, F.; Perez, A.; Griebenow, K.; Cao, X. L.; Nafie, L. A. The Structure of Tri-Proline in Water Probed by Polarized Raman, Fourier Transform Infrared, Vibrational Circular Dichroism, and Electric Ultraviolet Circular Dichroism Spectroscopy. Biopolymers 2003, 71, 558-568.

(18) Dukor, R. K.; Keiderling, T. A. Reassessment of the Random Coil Conformation - Vibrational CD Study of Proline Oligopeptides and Related Polypeptides. Biopolymers 1991, 31, 1747-1761.

(19) Dukor, R. K.; Keiderling, T. A.; Gut, V. Vibrational CircularDichroism Spectra of Unblocked Proline Oligomers. Int. J. Pept. Protein Res. 1991, 38, 198-203.

(20) Kuemin, M.; Engel, J.; Wennemers, H. Temperature-Induced Transition between Polyproline I and Ii Helices: Quantitative Fitting of Hysteresis Effects. J. Pept. Sci. 2010, 16, 596-600.

(21) Zanna, N.; Milli, L.; Del Secco, B.; Tomasini, C. Factors Affecting the Stabilization of Polyproline II Helices in a Hydrophobic Environment. Org. Lett. 2016, 18, 1662-1665.

(22) Chen, K.; Liu, Z. G.; Kallenbach, N. R. The Polyproline II Conformation in Short Alanine Peptides Is Noncooperative. Proc. Natl. Acad. Sci. U. S. A. 2004, 101, 15352-15357.

(23) Woody, R. W. Circular Dichroism Spectrum of Peptides in the Poly(Pro)II Conformation. J. Am. Chem. Soc. 2009, 131, 8234-8245.

(24) Kelly, S. M.; Jess, T. J.; Price, N. C. How to Study Proteins by Circular Dichroism. Biochim. Biophys. Acta, Proteins Proteomics 2005, 1751, 119-139.

(25) Bulheller, B. M.; Rodger, A.; Hirst, J. D. Circular and Linear Dichroism of Proteins. Phys. Chem. Chem. Phys. 2007, 9, 2020-2035.

(26) Nordén, B.; Rodger, A.; Dafforn, T. R. Linear Dichroism and Circular Dichroism: A Textbook on Polarized-Light Spectroscopy; RSC: Cambridge, U.K., 2010.

(27) Rodger, A.; Nordén, B. Circular Dichroism and Linear Dichroism; Oxford University Press: Oxford, U.K., 1997.

(28) Kalyanasundaram, K.; Thomas, J. K. Environmental Effects on Vibronic Band Intensities in Pyrene Monomer Fluorescence and Their Application in Studies of Micellar Systems. J. Am. Chem. Soc. 1977, 99, 2039-2044.

(29) Winnik, F. M. Photophysics of Preassociated Pyrenes in Aqueous Polymer-Solutions and in Other Organized Media. Chem. Rev. 1993, 93, 587-614.

(30) Wilhelm, M.; Zhao, C.-L.; Wang, Y.; Xu, R.; Winnik, M. A.; Mura, J.-L.; Riess, G.; Croucher, M. D. Poly(Styrene-Ethylene Oxide) Block Copolymer Micelle Formation in Water: A Fluorescence Probe Study. Macromolecules 1991, 24, 1033-1040.

(31) Johnsson, M.; Hansson, P.; Edwards, K. Spherical Micelles and Other Self-Assembled Structures in Dilute Aqeuous Mixtures of Poly(Ethylene Glycol) Lipids. J. Phys. Chem. B 2001, 105, 8420-8430. 